\title{
STRAY CURRENT CORROSION MITIGATION, TESTING AND MAINTENANCE IN DC TRANSIT SYSTEM
}

\author{
S.A. MEMON ${ }^{1} \&$ P. FROMME ${ }^{2}$ \\ ${ }^{1}$ Arup North America, Houston, Texas. \\ ${ }^{2}$ University College London, London, UK.
}

\begin{abstract}
Stray current corrosion in direct current (dc) transit systems occurs because of the mechanism of current transfer between metals and a conductive electrolyte such as concrete, soil and water. Stray current reactions can be considered as a special case in that the anode (point of current discharge) may be at a considerable distance from the cathode (point of current pickup). The risk of stray current corrosion arising from the operation of dc-powered transit system is difficult to eliminate completely. However, suitable design of de traction power systems and structures carrying the railways can significantly reduce the risk of corrosion both to the transit system structures and third-party structures.

Stray currents can cause safety risks, thus making the design of stray current mitigation, testing and maintenance an important element of the holistic design for a dc transit system. Based on the results of the literature research, interviews with over two dozen dc rail transit systems, and testing of dc rail tracks, this paper presents and analyses various mitigation methods currently in use in the industry to control stray current corrosion. Recommendations for the testing (monitoring) and maintenance procedures to keep the stray current leakage and the related corrosion in control are then presented. Keywords: corrosion, direct current transit system, leakage current, rail potential, rail-to-earth potential, stray current, stray current corrosion, stray current testing, substation spacing, testing and maintenance of dc operating transit system.
\end{abstract}

\section{INTRODUCTION}

Stray current corrosion has been a cause of concern for dc rail transit agencies, electrolysis committees, utility owners and providers all across the globe. Over the years various stray current control and collection methods have been adopted by different transit agencies with varying results. The mitigation methods usually depend on various factors including but not limited to geographical location of the transit system, physical environment (weather), soil investigations, economic considerations and other elements. These methods are seldom defined in the transit agency design criteria especially when it is an older agency. In general most of the transit agencies in Europe and often outside of Europe follow the BS EN 50162:2004 [1] \& BS EN 50122-2:2010 [2] - BSI (British Standards Institution) standards.

In the US an ASTM designation G 165 -99 (ASTM [3]), which was issued in 1999 as a standard practice for determining rail-to-earth resistance, is also used by the transit agencies to carry out the rail-to-earth testing. Besides the above-mentioned standards there are no other national standards or guidelines for stray current leakage and corrosion control that can be used by the transit agencies in the US (National Research Council [4]). In the absence of any defined standards or guidelines the transit agencies occasionally end up choosing from a vast array of mitigation methods. These mitigation methods are adopted based on the knowledge of previously completed projects instead of the agency choosing them based

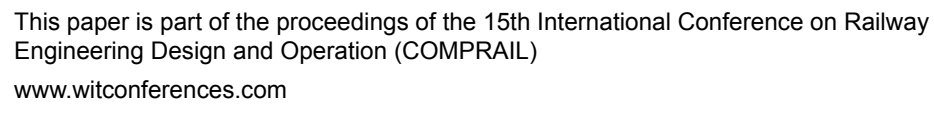


on applicability and understanding of project-specific factors, surveys, studies and systems design carried out for that specific transit system.

Thus to understand the stray current design process, used by various transit agencies, an initial desk study of numerous dc-powered transit systems was performed. This was used to collect pertinent information on design criteria, performance specifications, constructability issues and physical environment as it relates to stray current mitigation decisions. Based on the findings of the literature review a mix of 30 transit agencies (including US and international agencies) were contacted. A questionnaire was emailed to these transit agencies to gather information on their existing stray current mitigation and collection procedures, methods of testing and measurement, criteria for acceptable levels including rail-to-earth potential, and agency-specific existing and/or previous issues.

This paper highlights the most common mitigation, testing and maintenance methods narrowed down during the study that have been successfully adopted by these agencies in effectively controlling the stray current corrosion.

\section{STRAY CURRENT CORROSION}

The operating current for the electric traction power supply flows through the overhead catenary system or the third rail to the vehicle and returns to the substation through the return circuit. The return circuit includes numerous conductors that help complete the path of the return current to the substation. Running rails are typically the most widely used conductors for the return of electric current. Since perfect insulation does not exist and that rail has a finite resistance, the return current leaks into the earth and finds its way to the substation via the path of least resistance. This current that leaks into the earth by taking the path of least resistance is called stray current and the resulting corrosion is called stray current corrosion.

In dc-powered rail transit systems the stray current will follow any path of least resistance (rather than the rail), if not designed properly, to return to the substation. This can cause significant corrosion to the metallic structures along the rail transit system where the current leaves the conductor and potentially to third-party buried infrastructure. Hence measures need to be taken to contain stray current at the source by providing suitable insulation and/or isolation of the rail to prevent the current flow into the earth.

Some transit systems use the fourth rail system for the return of current which is typically an insulated conductor fourth rail, electrically isolated from the running rails and the surrounding soil. This fourth rail collects the current and returns it to the substation. However, fourth rails are not often used due to limited transit system construction budgets.

\section{MITIGATION AND CONTROL METHODS}

Early project surveys (including the stray current specific line items), commonly referred to as baseline surveys, are an integral part of the initial design of stray current corrosion mitigation. Baseline surveys consist of the following important elements (Moody [5]):

- Utility location information and coordination - this includes collecting/measuring voltage potential on existing utility structures.

- Soil corrosion characteristics - this includes existing ground testing.

- Atmospheric corrosion characteristic - this includes weather variations.

A baseline survey plays a vital role in the design and mitigation of stray current in dc-powered transit system which helps develop a planned approach with foreseeable milestones from inception to the operation stage of the transit system (Memon [6]). 
Depending on the findings of the baseline survey and traction power design during the design of the dc-powered rail transit system, steps must be taken to incorporate stray current controls. These steps should start with controlling the stray current at the source which is commonly referred to as 'control at source'. This should then subsequently be followed by mitigation of the stray current, the collection of the stray current leakage and then finally the ongoing planned maintenance and testing of the tracks.

Contingent on the type of track this 'control at source' is accomplished by frequently spaced substations, cross-bonding, rail resistivity, use of insulated track fasteners, rail boots, and improved coatings, maintaining a continuous electrical path, and isolating the rail in the yards (Fromme \& Memon [7]).

\subsection{Track type}

Embedded track design requires a more complex level of electrical isolation as compared to ballasted track and thus demands a more aggressive approach to control the stray current leakage. The following are some of the key elements specific to embedded track design that must be evaluated at an early design level to avoid potential stray current leakage issues:

- Drainage at and around the tracks

- Rail boot construction (joints in particular)

- Grade crossings

- Insulating fasteners

- Special construction like bathtub isolation

- Collection mats

\subsection{Substation spacing}

This technique reduces the feeding distances and the amount of current to be returned to any one point, resulting in the reduction of track voltage drop, thereby reducing the amount of current which will stray away from the rails. Technology papers by the Bureau of Standards on leakage of currents from electric railways, issued in 1916, by Stratton, M'Collum and Logan (Stratton et al. [8]), explain the importance of reducing the feeding distance to minimize the stray current leakage for both grounded and ungrounded systems with the use of mathematical expressions.

Considering the marked effect on the reduction of the stray currents and overall potentials due to the reduction in the feeding distance, average feeding distances between the substations have been reduced to two to three miles on a typical dc-operated light rail system (Fig. 1).

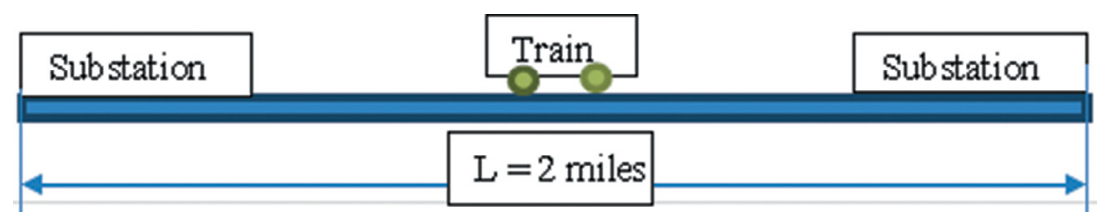

Figure 1: Substation spacing. 


\subsection{Rail resistivity and cross-bonding}

Rail resistivity is mostly based on the type of rail used and its cross section and weight. Different size and type of rail are provided by different manufacturers. Based on the design loads, design life, cost and other track requirements the transit agency decides which vendor and rail section to select.

The use of heavy rail sections and suitably bonded rail joints were one of the earliest implemented mitigation methods for the control of stray current. The evolution of rail sections and steel along with other metal compositions has continued throughout the years and across the globe. With time rail sections have been improved in cross section, length and the method of joining the two sections of rail. Increasing the cross-sectional area or size of the rail is achieved by using standard size rails ranging from 90 to 120 pounds (115 RE tee is the commonly used rail with a longitudinal resistance of around $40-80 \mathrm{~m} \Omega / \mathrm{km}$ ) (Cotton \& Charalambous [9]).

Welded joints are used to provide conductivity equal to or greater than the continuous rail. These joints are less subject to failure compared to other forms of rail joints. Welding of rail lengths is thus used as the standard form of construction, especially in the embedded rails. This has not only proven instrumental in the reduction of stray current but also improved the performance of rail.

Cross-bonding between single-track and parallel-track rails is installed to ensure rail connectivity and to equalize the current flow between the rails, thus reducing voltage drop (rail potential). A frequent cross-bonding of tracks at an average of 500 to 1,000 feet is recommended.

\subsection{Resistance to earth and rail isolation}

Resistance of the ground immediately in contact with the rail depends primarily on the type of ground material that is in contact with the rail. Measures are taken to insulate the track from the earth to reduce the stray current process, thus reducing the corrosion of the base of the rails and other grounded steel structures for the sections of the rail that were embedded in the ground in urban areas.

As the current return path to the adjacent substation increases, the rail potential increases and similarly does the stray current. The track type along the track and in the immediate vicinity of the substation plays an important role in keeping the stray currents under control. It is a general understanding in the industry that the ballast section will have a high rail-toearth resistance and thereby a reduced stray current as compared to embedded track.

Tracks are regularly maintained to keep the vegetation out of the tracks, retaining the track clean, dry, and dirt- and salt-free to help preserve the resistivity of the rail-to-earth high by keeping them insulated from earth. Well-drained broken stone ballast or gravel ballast is used in non-embedded sections for its much higher resistance to stray current as compared to concrete, whereas for embedded tracks, the rail is typically isolated from the ground by a sealing compound or rail boot (Fig. 2).

\subsection{Isolation of rail in yards}

Stray current is reduced by isolating the track in the yards and storage areas by detaching it from the sections of the main track (Szeliga [11]). To protect the staff from electrical shock in the yards and shops the running rails are directly grounded and earthed back to the nearest substation via insulated cables. This results in excess leakage of stray current since the only 

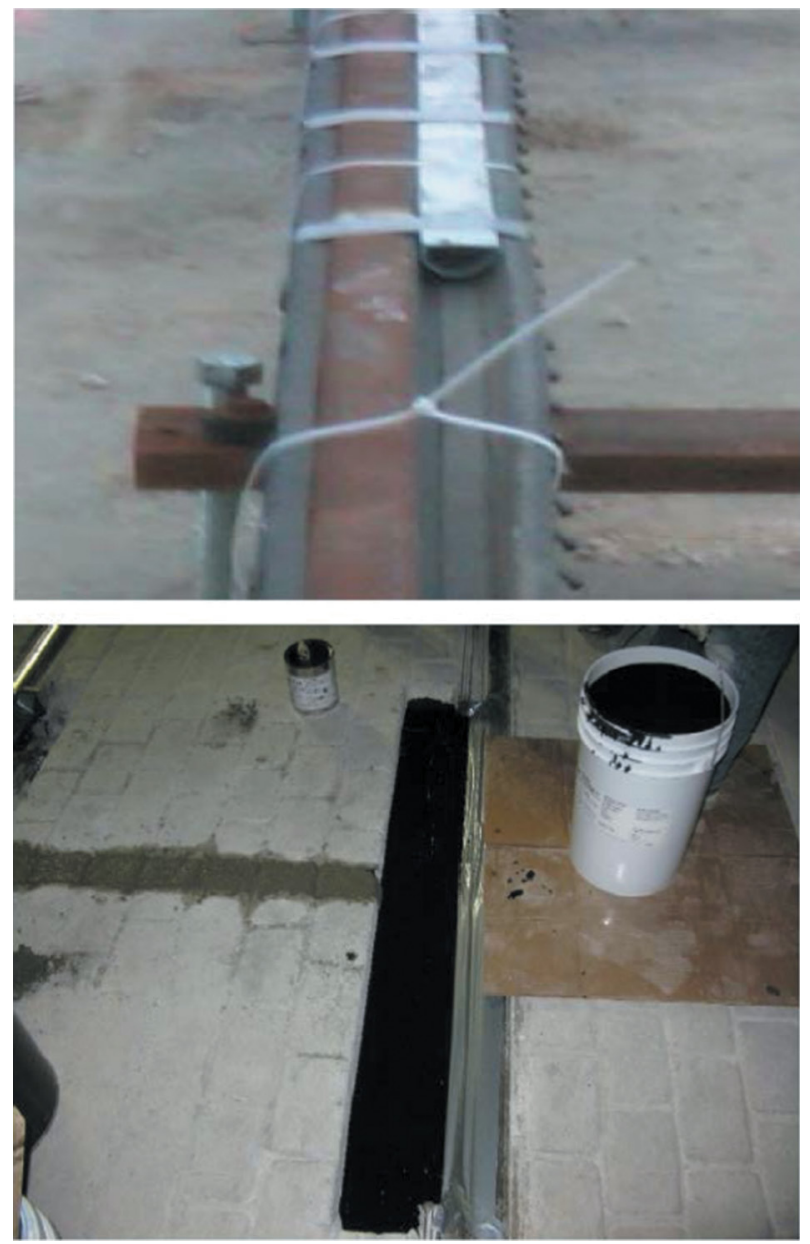

Figure 2: Rail boot (Memon \& Fromme [10]) and sealing compound replacing rail boot.

way back for the current to the substation is through the ground which contributes to the current leakage. Therefore, yard tracks are isolated from the main track and are provided with a dedicated substation.

\subsection{Ungrounded or floating system}

A floating system has no deliberate connection to earth and the stray currents are restricted by high rail-to-earth resistance using rail boot, rail coating and rail fasteners. However, this could potentially result in increased running rail voltage, as compared to the grounded system, causing safety concerns for the general public and transit agency staff. Though these safety concerns present a downside to the system, this system is preferred over the other systems because surveys conducted have shown that the floating system with ungrounded substations provides the best earthing system and keeps the potential within limits. Safety concerns are addressed with the use of overvoltage protection equipment and platform insulation procedures. 


\subsection{Drainage and insulating fasteners}

Maintaining proper drainage around the rail boot and the tracks is vital. Proper drainage measurements must be taken during construction with careful design of water flow at low elevations and other critical locations. In newer constructions it is recommended to provide a rubber boot flangeway to isolate the rail contact. Similarly, the use of insulating rail fasteners is also important. This is especially vital where the use of insulated clip-type fasteners for rail to tie connection and continuous welded sections are common.

\subsection{Collection mats}

For embedded tracks operating in city streets, stray current corrosion is a major concern to the track owners and utility and other infrastructure owners in the vicinity of the transit system. Stray current collection systems are sometimes necessary to control the current leakage on these systems. The goal of insulating the rail is to control the current at the source and minimize the stray current leakage. Thus the need for a collection mat can be eradicated if the level of stray current being produced by the transit system is controlled by rail insulation. Research shows that there will be a certain amount of stray current leakage in spite of these control measures. This leakage usually happens after a few years of track life or even earlier if the tracks are not maintained and tested routinely (based on the survey results).

Collection mats are used to intercept and retain stray current on embedded track sections which are laid on concrete slabs with steel reinforcement such as those in tunnels and viaduct. A stray current collection mat in these instances provides a low-resistance path to intercept and retain the stray current leaving the rails. These collection mats are continuously bonded together along their length to provide the stray current with a low-resistance path (Fig. 3) (Tzeng \& Lee [12]).

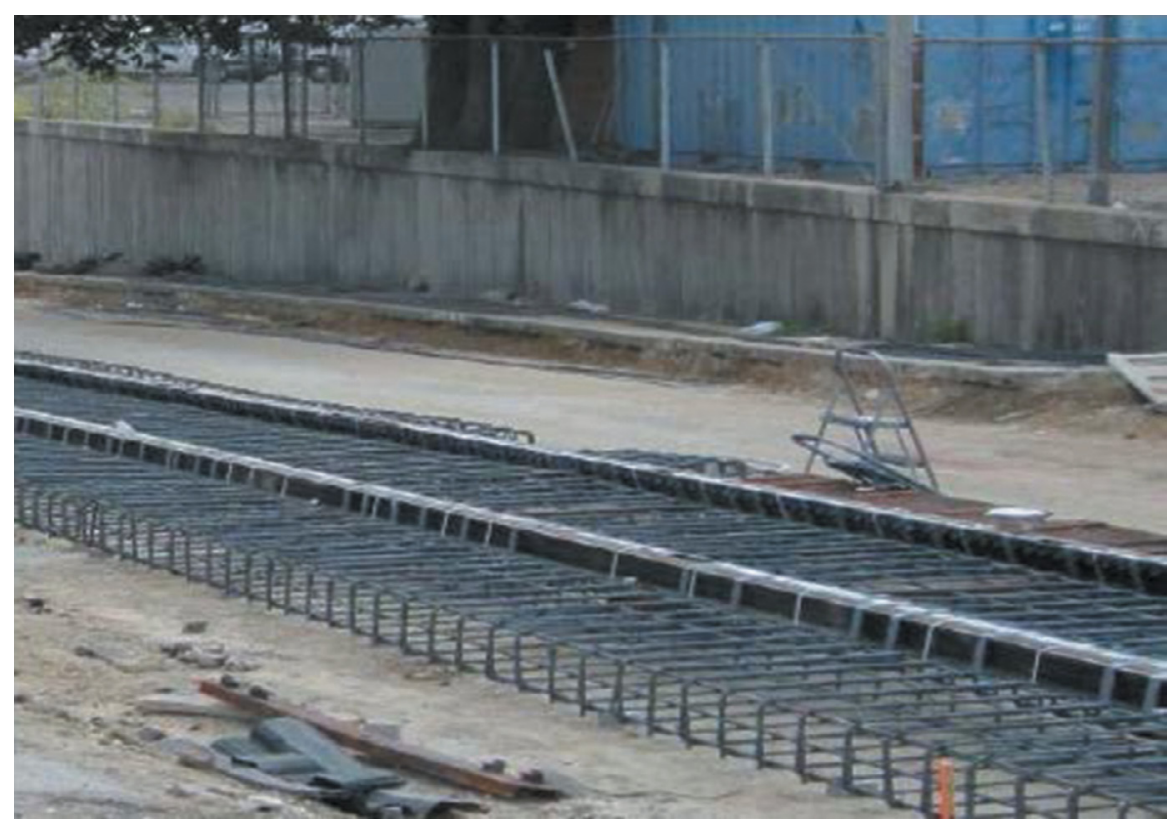

Figure 3: Reinforcement steel and collection mat for embedded track. 


\section{STRAY CURRENT TESTING AND MAINTENANCE}

Mitigation methods installed to control stray current corrosion require periodic testing and maintenance to ascertain their safe performance and effectiveness. Therefore, it is important to conduct regular inspection and testing of the tracks including the inspection and testing of any mitigation techniques installed by the transit system to ascertain that the stray current leakage is within limits and the mitigation measures are operational as designed (Memon [6]).

The transit agencies interviewed, in general, agreed on the need and importance of a well-thought-out testing and maintenance plan tailor-fitted to their geographical and system necessities.

\subsection{Coordination and communication}

The development of a coordinated effort to sustain effective stray current control requires education, communication and cooperation of all stakeholders and concerned parties. Communication is the foundation of the effort to achieve and maintain effective stray current control. Thus it is essential that regular exchange of information be maintained between the interested parties to develop an overall sustainability of effective and efficient stray current control.

Based on the results of the transit agency survey it was observed that the stray current issues were significantly less onerous in those transit systems which had corrosion committees located in reasonable geographic proximity. This shows that coordination and communication with the corrosion engineers and utility owners are the key elements in keeping the corrosionrelated problems under control.

\subsection{Stray current testing}

It is good transit industry practice to perform track-to-earth and utility-to-earth resistance testing prior to any revenue service operation to document the reference point characteristics and stray current activity of the system. These track-to-earth resistance values are used by the transit agencies and corrosion design consultants to achieve the control at source and thereby design and maintain the stray current mitigation and collection techniques. Based on the findings of the survey, following are some of the most commonly performed tests by the transit agencies (Memon \& Fromme [10]):

- Track-to-earth resistance survey - measures the resistance and helps in locating and isolating the track work discontinuities.

- Track slab current measurement - provides an insight into the magnitude and direction of possible current leakage from the rails.

- Structure (utility pipe)-to-soil potential measurement - helps identify whether the structure is influenced by stray current and the direction of the current flow.

- Audio frequency testing - helps in pinpointing the local low-resistance areas and is used in conjunction.

\section{STRAY CURRENT MAINTENANCE}

The key fundamental maintenance essentials to be carried out on the system must include the following:

- Visual inspection - this is the first level of defence in identifying stray current leakage areas and providing mitigation for them. 
- Rail isolation from conductive elements - this can be spotted during visual inspections and/or the testing of the system.

- Maintaining clean and dry tracks - it is imperative to control vegetation and design the tracks such that they drain properly and the water does not stand close to the rail boot and the tracks.

- Testing regime - working out a regular testing schedule to perform testing of the tracks in coordination with the corrosion consultant.

\section{CONCLUSION}

Of the many transit agencies interviewed (with testing being done at some of these) most of the ballasted section results showed that stray current leakage is under control and track-toearth resistance values are within the limiting values based on the agency's criteria. However, unlike ballasted sections, most of the embedded sections showed higher track-to-earth resistance values along at least one segment of the track. Some of these track sections were using a concrete flangeway which holds earth and debris that in return provides a path for the stray current. This along with the fact that the concrete repairs with time had spilled over the rail boot at many locations, which resulted in the creation of a contact with the rail thereby annulling the purpose of the rail boot isolation.

Drainage of storm water seems to be another common issue with several transit agencies. These drainage correction measurements must be taken into account during initial construction with careful design of water flow at low elevations and other critical locations. In newer constructions it is recommended to provide a rubber boot flangeway to isolate the rail contact with the earth.

Another issue observed was the inconsistency of the testing methods and frequency of testing. Testing methods should be adapted based on the age of the transit system, location of the tracks, type of the track bed, the type of structure under investigation and the source of leakage.

Lastly, it would be easier to implement most of the above-mentioned isolation, mitigation and collection options on a newer transit system with proper foresight and planning. However, not all the options and recommendations discussed here will apply to older systems or systems that are currently going through extension of their existing systems. In such instances it will be the responsibility of the design engineer/consultant in consensus with the transit agency/ owner to design the system that will keep the stray current corrosion to a minimum. The key to achieve a leakage-free transit system is to follow the logical sequence of the design process and then maintain a stringent maintenance and testing regime.

\section{REFERENCES}

[1] Protection against corrosion by stray current from direct current systems. BS EN 50162:2004 - BSI (British Standards Institution), 2004

[2] Railway applications - Fixed installations - Electrical safety, earthing and the return circuit. Part 2: Provisions against the effects of stray currents caused by DC traction systems. BS EN 50122-2:2010 - BSI, 2010.

[3] Standard Practice for Determining Rail-to-Earth Resistance. American Society for Testing and Material (ASTM) Designation: G 165-99, 1999

[4] Electrolytic Corrosion in DC Powered Transit Systems, IIT Research Institute, Chicago, IL, 8 Reports Prepared for the National Cooperative Transit Research and Development Program (NCTRP) Project 48-1, TRB, National Research Council, Washington DC, 1985-1987. 
[5] Moody, K.J., A cookbook for transit system stray current control. Presented at NACE Corrosion, Paper No. 14, New Orleans, LA. 1993.

[6] Memon, S. A., Understanding stray current mitigation, testing and maintenance on DC powered rail transit systems. Proceedings of the 2013 Joint Rail Conference, Knoxville, TN, USA, April 15-18, 2013.

[7] Fromme, P. \& Memon, S.A., Use of rail boot and collection mat to control the electrolysis of rail and utilities in DC powered transit agencies. Proceedings of the 2014 Joint Rail Conference, Colorado Springs, CO, USA, April 2-4, 2014.

[8] Stratton, S.W., M'Collum, B. \& Logan, K.H., Technology papers of the bureau of standards - leakage of currents from electric railways. Washington Government Printing Office. 1916.

[9] Cotton, I. \& Charalambous, C., Influence of soil structures on corrosion performance of floating-DC transit systems. IET Electric Power Applications, 1(1), pp. 9-16, 2007. DOI: $10.1049 /$ iet-epa:20050449.

[10] Memon, S.A. \& Fromme, P., Stray current corrosion and mitigation in DC transit systems. IEEE Electrification Magazine, 2, pp. 22-31, 2014. DOI: 10.1109/ MELE.2014.2332366.

[11] Szeliga, M. J., Stray Current Corrosion: The Past, Present and Future of Rail Transit Systems, NACE International: Houston, TX. ISBN 1-877914-57-6, 1994.

[12] Tzeng, Y.S. \& Lee, C.H., Analysis of rail potential and stray currents in a direct-current transit system. IEEE Transactions on Power Delivery, 25(3), pp. 1516-1525, 2010. DOI: 10.1109/TPWRD.2010.2040631. 